\title{
Energia Elétrica: Estudo comparativo entre empresas internacionalizadas e não internacionalizadas
}

\author{
Ricardo Lerche Eleutério ${ }^{1}$ \\ Nadia Wacila Hanania Vianna ${ }^{2}$
}

\begin{abstract}
Resumo
Empresas brasileiras, após 1990, têm buscado, com mais ênfase, o mercado internacional. Diferentes estudos têm apontado vantagens e desvantagens para o desempenho das empresas, advindas da internacionalização. Desempenho econômico-financeiro é uma das categorias de desempenho. Nesse sentido, e com relação às empresas do segmento energia elétrica, formulou-se a questão: empresas brasileiras de capital aberto, listadas na BM\&FBovespa, e internacionalizadas, tiveram desempenho econômico-financeiro diferenciado no período 2010-2013, em relação às não internacionalizadas? Questões subsidiárias foram adicionadas: quais foram as estratégias de entrada em novos mercados? Qual foi a motivação para o direcionamento ao cenário internacional? Foram feitas entrevistas com pessoas atuantes na área de relações com investidores das empresas internacionalizadas e pesquisa documental. Empresas entraram no mercado internacional a partir do modo greenfield, motivadas por questões econômicas. As empresas internacionalizadas apresentaram desempenho entre os melhores encontrados na amostra pesquisada. Os resultados não podem ser generalizados para as empresas não participantes da pesquisa.
\end{abstract}

Palavras-chave: Estratégia de internacionalização, Desempenho econômico-financeiro, Energia elétrica.

\section{Electrical Energy: Comparative study between internationalized companies and non-internationalized}

\begin{abstract}
Brazilian companies, especially from the 1990s, have been intending to act in the international scenario. Different studies have described advantages and disadvantages for companies' performance due to the internationalization. Financial performance is one of the performance categories. Considering this aspect, in relation to the companies in the Electric Power segment, a question was formulated: did the Brazilian publicly traded companies, listed on the BM\&FBovespa, which adopted internationalization strategies, have different economic and financial performance in the period 2010-2013, when compared to non-internationalized companies? Subsidiary questions were added: what were the strategies adopted by the internationalized companies to enter into new markets? What was the motivation for targeting the international scenario? Interviews were conducted with people working in the investor relation area of internationalized companies; documentary research also was conducted. Companies entered the international market through the greenfield mode, motivated by economic issues. Internationalized companies showed performance among the best found in the sample surveyed companies. The results cannot be generalized for companies not participating in the research.
\end{abstract}

Keywords: Internationalization strategy, Economic and Financial performance, Electrical energy.

\footnotetext{
${ }^{1}$ Mestre em Administração, Professor da FMU (Faculdades Metropolitanas Unidas), ricardo.eleuterio@uol.com.br

${ }^{2}$ Doutora em Administração, Professora pesquisadora do Programa de Mestrado em Administração da UNIP (Universidade Paulista), nhvianna@terra.com.br
} 


\section{INTRODUÇÃO}

O relatório da UNCTAD (United Nations Conference on Trade and Development) de 2012 apresenta dados sobre a economia mundial em relação ao quanto esta sofreu com as consequências da crise de 2008, que se iniciou no mercado imobiliário norte americano. Podese ter uma dimensão dessa crise, quando se verifica que, no período 2007-2012, os países em desenvolvimento participaram do montante do PIB (Produto Interno Bruto) mundial, com $74 \%$ e os países desenvolvidos participaram somente com $22 \%$ desse montante (UNCTAD, 2012).

O Brasil apresentou queda de 39\% no investimento direto realizado no exterior no período estudado, enquanto no setor de eletricidade, gás e outras utilidades houve um crescimento 87\%, conforme o Banco Central do Brasil (BCB, 2015). O benefício da internacionalização é salientado por vários autores, como: Dunning (2001) que destaca os incentivos fiscais, a possibilidade de se pagar salários menores do que no país de origem, além de acesso a recursos naturais e know-how; Gallina, Fleury e Bulba (2005) que apontam o reconhecimento mundial, a flexibilização da produção para outros países deve-se deslocar com base na taxa de câmbio e o aumento do faturamento da empresa; e por Macadar (2009) que ressalta o ganho em conhecimento tecnológico.

Assim, a questão norteadora da pesquisa realizada foi: "as empresas brasileiras de capital aberto listadas na BM\&FBovespa (sigla resultante da fusão entreBolsa de Mercadorias e Futuros e Bolsa de Valores de São Paulo), internacionalizadas, tiveram desempenho diferenciado no período de 2010-2013, em relação às outras, não internacionalizadas? " Em vista do exposto, foi analisado o desempenho de empresas sob a perspectiva econômicofinanceira, com base em índices e indicadores obtidos a partir de publicações divulgadas pelas próprias empresas.

Questões adicionais foram formuladas: quais foram as estratégias de entrada em novos mercados, adotadas pelas empresas internacionalizadas? Qual foi a motivação para o direcionamento ao cenário internacional?

Para essa pesquisa foram selecionadas empresas do setor de Utilidade Pública, do segmento Energia Elétrica, listadas na BM\&FBovespa e que são empresas propulsoras do desenvolvimento do país, na medida em que fornecem energia para todos os setores da economia.

No período estudado (2010 - 2013) o segmento de energia elétrica cresceu 10,66\%, compreendendo as matrizes energéticas: (i) hidráulica que reduziu a sua produção em 1,97\%; 
(ii) termo convencional que apresentou crescimento na produção em 148,48\%; (iii) termonuclear que cresceu somente 6,44\%; e (iv) eólica com crescimento de produção de $168,88 \%$. A matriz hidráulica correspondeu a $85,97 \%$ da produção no período, a matriz termo convencional correspondeu a $10,44 \%$, a matriz termonuclear correspondeu a 3,07\% e a matriz eólica, mesmo com grande crescimento, somente a $0,52 \%$ da produção energética no período (ONS, 2015). Os dados em Giga-Watt-Hora são apresentados na tabela 1:

Tabela 1 - Produção do segmento de energia elétrica no Brasil (GWH)

\begin{tabular}{lrrrr}
\hline & \multicolumn{1}{c}{2010} & \multicolumn{1}{c}{2011} & \multicolumn{1}{c}{2012} & \multicolumn{1}{c}{2013} \\
\hline Hidráulica & 422.893 & 450.236 & 411.178 & 414.555 \\
Termo convencional & 37.496 & 25.981 & 53.404 & 93.173 \\
Termonuclear & 14.515 & 15.658 & 16.038 & 15.449 \\
Eólica & 1.471 & 1.902 & 3.192 & 3.956 \\
\hline
\end{tabular}

Fonte: ONS (2015).

A principal matriz energética do Brasil é a fonte hidráulica, conforme tabela 1, que sofreu redução após o ano de 2011 e houve crescimento da fonte termo convencional, mais poluidora; a fonte termonuclear se mantém quase que constante durante esse período, com a utilização das usinas localizadas na cidade de Angra dos Reis (RJ), e a fonte eólica, a chamada fonte limpa, cresceu quase que o dobro no período estudado, só que essa fonte ainda está abaixo de 1,00\% do total da fonte de energia elétrica do país (ONS, 2015).

O sistema de energia elétrica brasileiro, desde 2004, é segmentado em três partes: Geração, Transmissão e Distribuição de energia. No ano de 2012 foi editada uma medida provisória $\mathrm{n}^{\mathrm{o}} 579$, convertida em lei 12.783 em 11/01/2013, em que as transmissoras e geradoras conseguiriam renovar os contratos de concessão desde que seus preços fossem norteados pela agência reguladora (ANEEL, 2015). Isso fez com que as empresas geradoras que atuavam em um mercado competitivo passassem a ter os preços regulados, voltando ao controle do governo federal no setor de energia elétrica.

O objetivo geral do presente estudo foi, portanto, analisar se as empresas brasileiras do segmento energia elétrica, listadas na BM\&FBovespa, que adotaram a estratégia de internacionalização, chegaram a um resultado econômico-financeiro diferenciado em relação aos seus pares não internacionalizadas, no período 2010-2013. Quanto aos objetivos específicos, foram os seguintes: (i) Identificar dentro desse segmento as empresas de capital nacional; (ii) Identificar as empresas que se internacionalizaram; (iii) Conhecer o modo de entrada das empresas no cenário internacional; (iv) Conhecer o período em que mercados internacionais foram buscados; e (v) Levantar dados econômico-financeiros. 
Cabe salientar, que foram estudadas empresas de capital nacional ${ }^{3}$ com ações negociadas na BM\&FBovespa, porque disponibilizam suas demonstrações contábeis financeiras para análise e o período estudado foi 2010 - 2013, porque nele a economia tornouse mais estável (pós crise que afetou os mercados mundiais) e em 2010 teve início a adoção das normas internacionais de contabilidade (IFRS) pelas empresas brasileiras com ações negociadas na BM\&FBovespa, o que facilitou a comparabilidade de seus demonstrativos financeiros.

O presente trabalho está estruturado da seguinte forma: introdução, apresentação do segmento energia elétrica, fundamentação teórica, metodologia de pesquisa, apresentação e análise de resultados obtidos e conclusões.

\section{O SEGMENTO ENERGIA ELÉTRICA}

Na BM\&FBovespa há 64 empresas do segmento Energia Elétrica, das quais 14 são holdings (sendo 6 de capital nacional, 5 de capital estrangeiro, 1 em recuperação judicial, 1 em liquidação e 1 sem informações), 21 de capital estrangeiro e 29 de capital nacional. Desse modo, as empresas e holdings internacionalizadas são 5 (Alupar, Companhia Energética de Minas Gerais-Cemig, Andrade Gutierrez Concessões - AGConcessões, Eletrobras e Eletropar) e as empresas e holdings não internacionalizadas são 30. As empresas internacionalizadas estudadas nesse trabalho foram a Alupar e a Cemig, porque têm o mesmo tempo de experiência internacional, pois se internacionalizaram no ano de 2007, participando do consórcio de concessão da Transchile. As empresas não internacionalizadas focalizadas no presente trabalho são 13.

O segmento energia elétrica no Brasil tem 4.369 empreendimentos em operação para a produção de energia elétrica, que dispõe de 136.776.897 kW de potência instalada; outros dados apresentados pela Aneel (2015) merecem destaque: estão em construção 183 usinas e mais 667 estão projetadas (ainda não iniciada a construção) o que aumentará em 40.537 .795 kW a capacidade de geração de energia elétrica do País.

Tabela 2 - Energia Elétrica - Empreendimentos em operação

\begin{tabular}{lrr}
\hline Tipo & Quantidade & \% de produção \\
\hline Central geradora hidrelétrica (CGH) & 498 & 0,24 \\
Central geradora eólica (EOL) & 272 & 4,4 \\
Pequena central hidrelétrica (PCH) & 476 & 3,51 \\
Central geradora solar fotovoltaica (UFV) & 317 & 0,01 \\
Usina termoelétrica (UTE) & 2.603 & 28,34
\end{tabular}

3 Principal grupo ou controlador acionário da empresa que tem a origem do seu capital no Brasil. 
ReFAE - Revista da Faculdade de Administração e Economia

Usina hidroelétrica (UHE)

201

62,04

Usina termonuclear (UTN)

Total

4.369

100

Fonte: Adaptada Aneel (2015a).

Conforme dados do Balanço Energético Nacional, ano base 2013, apresentado pela Empresa de Pesquisa Energética (EPE, 2014) houve crescimento de 10,79\% no período de 2010 até 2013 em oferta interna de energia elétrica (OIEE) medidos em GWH e em 7,81\% da relação entre OIEE (Oferta interna de energia elétrica) e a população, conforme estimativa da EPE, no mesmo período, conforme tabela 3.

Tabela 3 - Oferta Interna de Energia /PIB/População

\begin{tabular}{|c|c|c|c|c|}
\hline & 2010 & 2011 & 2012 & 2013 \\
\hline Oferta interna de energia OIE $10^{6}$ tep $)^{4}$ & 268,8 & 272,3 & 283,4 & 296,2 \\
\hline Oferta interna de energia elétrica OIEE - (Gwh) & 550.447 & 567.644 & 592.753 & 609.892 \\
\hline PIB $\left(10^{9}\right.$ US $\left.\$\right)$ & $2.179,60$ & $2.239,10$ & $2.262,20$ & $2.313,90$ \\
\hline População residente - POP & 196,4 & 198,3 & 200,1 & 201,9 \\
\hline OIE/PIB & 0,123 & 0,122 & 0,125 & 0,128 \\
\hline OIEE/POP & 2802 & 2862 & 2962 & 3021 \\
\hline
\end{tabular}

Fonte: EPE (2014).

\section{FUNDAMENTAÇÃO TEÓRICA}

\subsection{Indicadores financeiros}

O desempenho econômico-financeiro possibilita fazer avaliação ampla sobre vários aspectos da empresa, e o aprofundamento da análise só será possível a partir de uma série de cálculos de indicadores contábeis, que são obtidos sobre a situação passada, atual ou futura (projeções) da empresa.

Os indicadores econômico-financeiros estão classificados em quatro grupos: rentabilidade, liquidez, endividamento e análise de ações (ASSAF NETO; LIMA, 2011; MATARAZZO, 2010). A literatura internacional pesquisada sob os temas internacionalização, desempenho econômico financeiro e energia elétrica revelou 17 índices e indicadores, dos quais foram selecionados para a presente pesquisa: (i) liquidez corrente; (ii) liquidez geral; (iii) composição do endividamento; (iv) endividamento; (v) participação de capitais de terceiros; (vi) giro do ativo; (vii) ROA (Return On Assets); (viii) ROE (Return On Equity); (ix) margem líquida; e (x) margem operacional.

\subsection{Internacionalização}

4 Unidade de medida de energia ofertada em tonelada equivalente de petróleo (tep). 
Entende-se neste trabalho, a internacionalização “[...] como o envolvimento de uma empresa com o mercado de país diferente daquele onde se originou, ou seja, é uma estratégia seguida por empresas, objetivando a diversificação de mercados" (VIANNA; PISCOPO; RYNGELBLUM, 2013, p.212). A internacionalização pode dar-se por meio de três modos distintos de entrada: (i) exportação; (ii) contratual - licenciamento, franquias, aliança contratual e acordos técnicos; e (iii) por investimento - greenfield (desde o início, com construção do parque industrial), aquisição de empresas ou fusão (ROCHA; ALMEIDA, 2006).

Sob o tema internacionalização de empresas foram formuladas teorias que procuraram explicar como e porque as empresas buscaram outros mercados para atuar. Dentre elas, citemse as estratégicas (Resource Based View - $R B V$ e comportamento estratégico), comportamentais (Escola de Uppsala e Networks), econômicas (Paradigma Eclético, Ciclo de Vida e Poder de Mercado) e Born global. A seguir será apresentada uma síntese de cada uma dessas teorias.

Quadro 1 - Teorias de internacionalização

\section{Econômica}

- Paradigma Eclético (vantagens da localização, propriedade e internalização).

- Ciclo de Vida (deslocamento de produção de um país desenvolvido para outro, em desenvolvimento, que possua fatores de produção mais baratos e receba o produto como inovador).

- Poder de mercado (criação de barreiras de entrada a novos competidores).

\section{Estratégica}

- O processo de internacionalização seguido pela empresa está alinhado à orientação estratégica, norteadora do seu plano estratégico, e às vantagens competitivas que a empresa possui.

Born Global

- Empresas com atuação global já no momento da abertura, ou em menos de cinco anos após a fundação.

\section{Comportamental}

- Escola de Uppsala (internacionalização gradual: primeiro a empresa exporta, depois estabelece algum tipo de aliança estratégica, faz aquisições, e com o conhecimento desse mercado pode chegar até à instalação de unidades próprias.

- Networks (a empresa segue algum componente da sua rede de relacionamentos que se internacionaliza).

Fontes: Johanson; Vahlne (1977; 2009); Dunning (2001); Rocha; Almeida (2006); Ribeiro; Oliveira Jr; Borini (2012). Elaborado pelos autores.

\section{METODOLOGIA}

Após a realização de pesquisa bibliográfica, buscou-se empresas listadas na BM\&FBovespa (2013) que são classificadas em setores, ou em estágios similares da cadeia produtiva, mesmo tendo atividades diferentes. Foram selecionadas empresas para o estudo do setor de utilidade pública, do segmento energia elétrica.

Foi feita pesquisa descritiva documental de fonte primária, com documentos como objeto de investigação da pesquisa (MARTINS; THEÓPHILO, 2009). Inicialmente, foram 
utilizados dados retirados das demonstrações financeiras padronizadas (DFP) das empresas listadas na BM\&FBovespa para identificar as empresas com maior parte do capital nacional brasileiro, e conhecer quais dessas empresas são internacionalizadas. Foram excluídas dessa análise as empresas em recuperação judicial e aquelas que estão com as negociações de suas ações suspensas em bolsa.

Foram analisadas empresas brasileiras, internacionalizadas, ou não, do segmento energia elétrica, com ações negociadas na BM\&FBovespa no período 2010 - 2013. Foi considerado como desejável que as empresas internacionalizadas selecionadas para o estudo tivessem sido internacionalizadas em período semelhante, para que o tempo de experiência no mercado internacional não interferisse de modo substancial nos resultados.

\subsection{A amostra selecionada}

As empresas do segmento de energia elétrica, de maior parte do capital social nacional totalizam 35, porém muitas apresentam uma única demonstração financeira padronizada, reduzindo a análise para 23 empresas.

Quadro 1 - Empresas internacionalizadas

\begin{tabular}{|l|c|}
\hline \multicolumn{1}{|c|}{ Empresa } & Ano da Internacionalização \\
\hline Alupar Investimentos S/A & 2007 \\
\hline Cemig - Companhia Energética de Minas Gerais S/A & 2007 \\
\hline Eletropar Participações S/A & 1979 \\
\hline AGConcessões S/A & 2005 \\
\hline Eletrobrás - Centrais Elétricas Brasileiras S/A & 1979 \\
\hline
\end{tabular}

Elaborado pelos autores

Fonte: BM\&FBovespa (2013).

Por ter sido considerado como desejável que as empresas internacionalizadas selecionadas para o estudo tivessem sido internacionalizadas em período próximo, para que o tempo de experiência no cenário internacional não influenciasse de modo diferenciado os indicadores das empresas, escolheu-se para estudo a Cemig e a Alupar, ambas internacionalizadas em 2007.

O quadro 11 apresenta as 13 empresas não internacionalizadas do segmento de energia elétrica, que foram selecionadas para a pesquisa: CEB (Cia Energética Brasiliense), CEEE-D (Cia Estadual de Distribuição de Energia Elétrica), CEEE-GT (Cia Estadual de Geração e Transmissão de Energia Elétrica), Celesc (Centrais Elétricas de Santa Catarina), Celgpar (Cia Celg de Participações), Cesp (Cia Energética de São Paulo), Copel (Cia Paranaense de Energia), CPFL Energia, Emae (Empresa Metropolitana de Aguas e Energia), Equatorial, Light, Renova e Taesa (Transmissora Aliança de Energia Elétrica). 
Quadro 2 - Empresas não internacionalizadas

\begin{tabular}{|l|l|}
\hline Afluente Transmissão de Energia Elétrica S.A. & Afluente Geração de Energia Elétrica \\
\hline Rio Grande Energia S/A & Cia Estadual de Distr de Energia Elétrica S/A \\
\hline Cia Energética de Brasília S/A & Centrais Elétricas de Santa Catarina S/A \\
\hline $\begin{array}{l}\text { Cia Estadual de Geração e Transmissão de Energia } \\
\text { Elétrica S/A }\end{array}$ & Centrais Elétrica de Pernambuco S/A \\
\hline Centrais Elétrica do Pará S/A & Centrais Elétrica do Mato Grosso S/ \\
\hline Centrais Elétrica do Maranhão S/A & Cia de Eletricidade do Estado da Bahia S/A \\
\hline Cia Energética de São Paulo S/A & Cia Ener do Estado do Rio Grande do Norte S/A \\
\hline Cia Paranaense de Energia S/A & CPFL Energia S/A \\
\hline Cia Piratininga de Força e Luz & CPFL Geração de Energia S/A \\
\hline CPFL Energias Renováveis S/A & Empresa Metropolitana de Águas e Energia S/A \\
\hline Termopernambuco S/A & Itapebi Geração de Energia S/A \\
\hline Equatorial Energia S/A & Light Serviços de Eletricidade S/A \\
\hline Light S/A & Cia Paulista de Força e Luz \\
\hline Neoenergia S/A & Renova Energia S/A \\
\hline Proman- Produtores Energético de Manso S/A & Transmissora Aliança de Energia Elétrica S.A. \\
\hline
\end{tabular}

Elaborado pelos autores

Fonte: BM\&FBovespa (2013).

Do total de empresas do segmento de energia elétrica, não fizeram parte do estudo, pelos motivos a seguir descritos:

Empresas participantes do grupo Neoenergia: Afluente Transmissão de Energia Elétrica, Afluente Geração de Energia Elétrica; Cia de Eletricidade do Estado da Bahia, Cia Energética do Estado do Rio Grande do Norte, Centrais Elétrica Pernambuco, Itapebi Geração Elétrica e Termopernambuco, apresentam informações consolidadas.

Empresas do grupo Equatorial: Celpa (Cia Energética do Pará) estava em recuperação judicial em 2013 e Cemar (Cia Energética do Maranhão) apresentam informações consolidadas.

$\checkmark \quad$ Proman (Produtores energéticos de Manso) possui balanços somente até 2012.

$\checkmark \quad$ Empresas participantes do grupo CPFL Energia: Rio Grande Energia, Cia Paulista de Força e Luz, Cia Piratininga de Força e Luz, CPFL Geração de Energia apresentam informações consolidadas.

\section{$\checkmark \quad$ CPFL Renováveis informações a partir de 2011.}

$\checkmark \quad 524$ Participações que não apresenta em seu site a origem de seu capital; a GTD Participações que está fora da bolsa e não apresenta informações

Empresas de capital estrangeiro: grupo AES, Ampla energia, Baesa (Energética Barra Grande), Brasiliana, Cachoeira, Coelce, grupo Energisa, Elektro, Desenvix, grupo EPD, geração Paranapanema, Tractebel e Transmissão Paulista;

AGConcessões que apresenta sua internacionalização com a concessão de rodovias no México e possui participações na Light, Cemig. A Bonaire é uma holding 
constituída por fundos de pensão ${ }^{5}$ que possuem ações de empresas no mercado, a Eletrobras que se internacionalizou em 1979 com a construção de Itaipu, a Eletropar que é a principal acionista da Eletrobrás, a Eneva que está em recuperação judicial, a Fortpart que está em liquidação, a Rede Energia que foi vendida ao grupo Energisa, a Redentor que pertence ao grupo Equatorial e a Uptick que possui um único objetivo que é a participação na Cosern.

\section{2 Índices econômico-financeiros: hipótese e verificação}

Formulou-se a seguinte hipótese de pesquisa "empresas internacionalizadas do segmento apresentam no período, indicadores econômico-financeiros melhor avaliados em relação àqueles de empresas não internacionalizadas”.

Para verificação da hipótese, tomou-se por base o quartil, medida da estatística descritiva. Segundo Martins e Domingues (2011), quartis são medidas de posição, separatrizes de um conjunto de dados, ou seja, que separam de $25 \%$ em $25 \%$ a distribuição dos dados. Considerou-se como melhor posicionamento para indicadores de liquidez e rentabilidade resultado superior ao terceiro quartil $\left(\mathrm{Q}_{3}\right)$, e para os indicadores de endividamento resultado abaixo do primeiro $\left(\mathrm{Q}_{1}\right)$ quartil (CUNHA; MARTINS; ASSAF NETO, 2012). Também foi realizado o teste não paramétrico de Mann-Whitney, para a diferença entre as médias de índices de empresas internacionalizadas e não internacionalizadas. Observe-se que esse teste foi escolhido porque não exige que as variáveis sigam distribuição normal.

Inicialmente calculou-se quartis para cada indicador e ano, e considerou-se o posicionamento no intervalo quartílico dos índices das empresas selecionadas relativamente às demais amostradas do segmento.

Em seguida, foram estabelecidas notas avaliativas para cada intervalo de $25 \%$ da distribuição, sendo notas de 1 até 4 , onde a nota 1 é considerada a pior nota e a nota 4 a melhor nota. Esse procedimento de avaliação foi adaptado de Matarazzo (2010), e conforme a interpretação que deve ser dada ao índice, aquele que recaiu no primeiro intervalo quartílico (inferior a $\mathrm{Q}_{1}$ ) recebeu nota 1 (para índices de liquidez e rentabilidade) ou 4 (para índices de endividamento) e, inversamente, aquele que recaiu no quarto intervalo quartílico (superior a $\mathrm{Q}_{3}$ ) recebeu nota 4 (para índices de liquidez e rentabilidade) ou 1 (para índices de endividamento).

5 São entidades fechadas de previdência, constituída por empresas, com o objetivo de realizar investimentos para garantir uma complementação da aposentadoria aos empregados que se associou ao plano (ASSAF NETO; LIMA, 2011).

ReFAE - Revista da Faculdade de Administração e Economia, v. 8, n. 2, p. 155-171, 2017 


\subsection{Internacionalização: motivação e estratégia}

Foram feitas entrevistas semiestruturadas com pessoas atuantes na área de relações com investidores das empresas internacionalizadas, segundo roteiro preparado com base nas teorias de internacionalização sumarizadas no Quadro 1.

\section{RESULTADOS E ANÁLISE}

\subsection{Internacionalização da Alupar e Cemig}

Embora não tenham sido obtidas todas as informações buscadas sobre o processo de internacionalização das empresas, é possível considerar que a conquista de melhor retorno financeiro para as empresas, em relação ao mercado interno foi a motivação para internacionalizar, o que é salientado pela teoria econômica (o paradigma eclético, DUNNING, 2001), dadas as vantagens econômicas encontradas no Chile, visto que a regulamentação vigente no país, possibilita aos investidores a captação de recursos no mundo, em dólar, com taxa de juros mais baixa, e consequente possibilidade de melhora no retorno financeiro.

As informações a seguir foram obtidas dos sites das empresas, em artigos científicos, dissertações e teses, em sites de busca com o nome das empresas usados como palavraschave, e em sites relacionados ao segmento energia elétrica. Respostas aos questionamentos efetuados foram apenas parcialmente fornecidas pelos responsáveis pela área de Relações com investidores (Alupar), e área de Imprensa (Cemig).

\subsubsection{Alupar}

Com a entrada de empresas estrangeiras no Brasil e consequente redução no retorno financeiro, foram feitas pesquisas nos países da América do Sul, buscando conhecer aqueles que tivessem regulamentação do setor muito parecida com a do Brasil, e com menor risco político. No que se refere à transmissão de energia, o Chile foi escolhido porque o retorno dos investimentos é em dólar, e devido à regulamentação vigente no país, os investidores conseguem captar recursos no mundo, em dólar, com taxa de juros mais baixa, e com isso existe a possibilidade de melhora no retorno financeiro. Quanto à geração de energia, a empresa adquire 65\% da La Virgen S.A.C., no Peru, em 2013, obtendo concessão por prazo indeterminado, e em 2011 tem autorização para atuar na Colômbia (ALUPAR, 2015). 


\subsubsection{Cemig}

Para a Cemig, a internacionalização foi a ocasião para diversificar investimentos. Participou de projeto no Chile juntamente com a Alupar, e até o término do período estudado não participou de nenhum outro na área internacional. A empresa, porém, mantém parceria em uma linha de transmissão no Chile com a Empresa Lusa do Chile (CEMIG, 2015).

\subsection{Dados econômico-financeiros das empresas}

Foram calculados os indicadores econômico-financeiros, conforme as expressões contidas no quadro 12, para cada ano do período estudado (Tabelas 4 a 7). Em seguida foram calculados os quartis de cada indicador em cada ano, com auxílio do software Excel 2013 (Tabela 8).

Tabela 4 - Indicadores referentes ao ano de 2010

\begin{tabular}{|c|c|c|c|c|c|c|c|c|c|c|}
\hline & $\begin{array}{l}\text { Liquidez } \\
\text { corrente }\end{array}$ & $\begin{array}{l}\text { Liquidez } \\
\text { geral }\end{array}$ & $\begin{array}{l}\text { Composição do } \\
\text { Endividamento }\end{array}$ & Endividamento & $\begin{array}{c}\text { Participação de } \\
\text { capital de } \\
\text { terceiros }\end{array}$ & $\begin{array}{l}\text { Giro do } \\
\text { Ativo } \\
\text { (vezes) }\end{array}$ & ROA & ROE & $\begin{array}{l}\text { Margem } \\
\text { liquida }\end{array}$ & $\begin{array}{c}\text { Margem } \\
\text { operacional }\end{array}$ \\
\hline Alupar & 2,18 & 1,80 & $22,44 \%$ & $55,71 \%$ & $230,45 \%$ & 0,13 & $13,15 \%$ & $32,29 \%$ & $60,91 \%$ & $75,87 \%$ \\
\hline Cemig & 1,26 & 1,52 & $29,00 \%$ & $65,80 \%$ & $192,40 \%$ & 0,15 & $13,38 \%$ & $19,68 \%$ & $46,28 \%$ & $32,41 \%$ \\
\hline CEB & 0,73 & 0,88 & $44,67 \%$ & $113,96 \%$ & $193,98 \%$ & 0,24 & $10,44 \%$ & $2,60 \%$ & $6,38 \%$ & $10,03 \%$ \\
\hline CEEE-D & 0,45 & 1,61 & $40,19 \%$ & $62,11 \%$ & $163,94 \%$ & 0,05 & $-5,16 \%$ & $-13,63 \%$ & $-114,44 \%$ & $-10,69 \%$ \\
\hline CEEE-G & 0,95 & 2,37 & $29,71 \%$ & $42,23 \%$ & $73,11 \%$ & 0,08 & $0,03 \%$ & $6,28 \%$ & $47,64 \%$ & $0,41 \%$ \\
\hline Celesc & 1,02 & 1,63 & $38,81 \%$ & $61,20 \%$ & $157,76 \%$ & 0,13 & $7,15 \%$ & $14,10 \%$ & $41,54 \%$ & $8,86 \%$ \\
\hline Celgpar & 0,29 & 0,91 & $65,69 \%$ & $109,53 \%$ & $-544,96 \%$ & 0,03 & $7,68 \%$ & $50,05 \%$ & $-300,71 \%$ & $21,78 \%$ \\
\hline Cesp & 0,54 & 2,25 & $18,83 \%$ & $44,53 \%$ & $80,28 \%$ & 0,08 & $0,92 \%$ & $0,89 \%$ & $6,16 \%$ & $5,98 \%$ \\
\hline Copel & 1,64 & 1,37 & $38,65 \%$ & $73,23 \%$ & $59,51 \%$ & 0,21 & $18,79 \%$ & $9,16 \%$ & $52,48 \%$ & $24,41 \%$ \\
\hline CPFL & 0,88 & 1,51 & $33,28 \%$ & $66,35 \%$ & $197,15 \%$ & 0,14 & $16,07 \%$ & $23,11 \%$ & $56,95 \%$ & $26,80 \%$ \\
\hline Emae & 1,24 & 3,54 & $26,85 \%$ & $28,27 \%$ & $39,42 \%-$ & 0,04 & $-4,09 \%$ & $1,72 \%$ & $-28,30 \%$ & $-32,43 \%$ \\
\hline Equatorial & 1,65 & 1,63 & $33,25 \%$ & $61,22 \%$ & $157,83 \%$ & 0,21 & $15,51 \%$ & $22,51 \%$ & $41,29 \%$ & $28,24 \%$ \\
\hline Light & 1,09 & 1,53 & $34,91 \%$ & $65,29 \%$ & $188,12 \%$ & 0,20 & $14,75 \%$ & $17,27 \%$ & $30,68 \%$ & $21,74 \%$ \\
\hline Renova & 8,39 & 3,02 & $12,14 \%$ & $33,13 \%$ & $49,54 \%$ & 0,06 & $3,65 \%$ & $0,52 \%$ & $6,02 \%$ & $42,72 \%$ \\
\hline Taesa & 3,51 & 2,21 & $14,92 \%$ & $45,19 \%$ & $82,43 \%$ & 0,16 & $15,93 \%$ & $17,09 \%$ & $58,88 \%$ & $91,29 \%$ \\
\hline
\end{tabular}

Fonte: Calculado pelos autores, conforme dados divulgados pelas empresas em 2010.

A Alupar apresentou os índices de liquidez corrente, composição do endividamento, ROE, margem líquida e margem operacional acima do terceiro quartil de 2010 e a Cemig apresentou índices entre o segundo e terceiro quartil em liquidez corrente, composição do endividamento, giro do ativo, ROA, ROE, margem líquida e margem operacional. A empresa Renova apresentou seis índices acima do terceiro quartil e a Taesa apresentou cinco índices acima do terceiro quartil no ano de 2010. 
ReFAE - Revista da Faculdade de Administração e Economia

Tabela 5 - Indicadores referentes ao ano de 2011

\begin{tabular}{|c|c|c|c|c|c|c|c|c|c|c|}
\hline & $\begin{array}{l}\text { Liquidez } \\
\text { corrente }\end{array}$ & $\begin{array}{l}\text { Liquidez } \\
\text { geral }\end{array}$ & $\begin{array}{l}\text { Composição do } \\
\text { Endividamento }\end{array}$ & Endividamento & $\begin{array}{c}\text { Participação de } \\
\text { capital de } \\
\text { terceiros }\end{array}$ & $\begin{array}{l}\text { Giro do } \\
\text { Ativo } \\
\text { (vezes) }\end{array}$ & ROA & ROE & $\begin{array}{l}\text { Margem } \\
\text { liquida }\end{array}$ & $\begin{array}{c}\text { Margem } \\
\text { operacional }\end{array}$ \\
\hline Alupar & 1,63 & 1,78 & $25,54 \%$ & $56,12 \%$ & $234,64 \%$ & 0,13 & $12,42 \%$ & $28,64 \%$ & $52,23 \%$ & $65,60 \%$ \\
\hline Cemig & 0,71 & 1,65 & $45,08 \%$ & $60,58 \%$ & $153,83 \%$ & 0,20 & $18,26 \%$ & $20,70 \%$ & $41,24 \%$ & $34,20 \%$ \\
\hline CEB & 0,70 & 0,90 & $46,18 \%$ & $111,48 \%$ & $190,91 \%$ & 0,24 & $13,78 \%$ & $6,18 \%$ & $14,98 \%$ & $12,78 \%$ \\
\hline CEEE-D & 1,25 & 2,16 & $55,23 \%$ & $46,27 \%$ & $212,35 \%$ & 0,05 & $-3,61 \%$ & $-16,55 \%$ & $-71,00 \%$ & $-10,00 \%$ \\
\hline CEEE-G & 2,13 & 2,36 & $38,22 \%$ & $42,36 \%$ & $73,48 \%$ & 0,09 & $2,08 \%$ & $4,07 \%$ & $25,40 \%$ & $16,06 \%$ \\
\hline Celesc & 1,11 & 1,64 & $40,91 \%$ & $60,94 \%$ & $138,21 \%$ & 0,17 & $8,61 \%$ & $14,18 \%$ & $36,20 \%$ & $10,93 \%$ \\
\hline Celgpar & 0,27 & 0,80 & $65,08 \%$ & $125,61 \%$ & $-1034,48 \%$ & 0,04 & $9,26 \%$ & $110,90 \%$ & $-302,98 \%$ & $20,60 \%$ \\
\hline Cesp & 0,61 & 2,24 & $19,68 \%$ & $44,55 \%$ & $80,33 \%$ & 0,08 & $5,31 \%$ & $1,07 \%$ & $7,22 \%$ & $32,77 \%$ \\
\hline Copel & 1,80 & 1,37 & $29,19 \%$ & $73,14 \%$ & $59,63 \%$ & 0,24 & $20,09 \%$ & $9,95 \%$ & $50,75 \%$ & $24,91 \%$ \\
\hline CPFL & 1,19 & 1,74 & $23,86 \%$ & $57,54 \%$ & $220,53 \%$ & 0,09 & $11,44 \%$ & $18,50 \%$ & $51,87 \%$ & $29,37 \%$ \\
\hline Emae & 1,21 & 3,14 & $38,77 \%$ & $31,82 \%$ & $46,67 \%-$ & 0,05 & $-8,08 \%$ & $-5,29 \%$ & $69,19 \%$ & $-55,76 \%$ \\
\hline Equatorial & 1,34 & 1,59 & $36,77 \%$ & $62,97 \%$ & $170,06 \%$ & 0,21 & $13,78 \%$ & $19,56 \%$ & $34,98 \%$ & $23,65 \%$ \\
\hline Light & 1,37 & 1,42 & $25,61 \%$ & $70,67 \%$ & $240,90 \%$ & 0,15 & $9,55 \%$ & $9,64 \%$ & $18,78 \%$ & $15,11 \%$ \\
\hline Renova & 2,30 & 1,73 & $19,16 \%$ & $57,76 \%$ & $136,76 \%$ & 0,02 & $0,34 \%$ & $-1,77 \%$ & $-47,00 \%$ & $15,11 \%$ \\
\hline Taesa & 0,94 & 1,53 & $39,12 \%$ & $65,30 \%$ & $188,15 \%$ & 0,14 & $14,73 \%$ & $21,99 \%$ & $53,09 \%$ & $95,89 \%$ \\
\hline
\end{tabular}

Fonte: Calculado pelos autores, conforme dados divulgados pelas empresas em 2011.

A Alupar apresentou a composição de endividamento, o ROE, a margem líquida e a margem operacional entre os melhores resultados da amostra estudada; a Cemig apresentou o ROA e a margem operacional no ano de 2011 crescente em relação a 2010, reduzindo o endividamento, que passou de 65,80\% (2010) para 60,58\% (2011) e a participação de capital de terceiros, que passou de 192,40\% (2010) para 153,83\% (2011). As empresas não internacionalizadas com mais destaque nesse ano foram a Taesa, a Emae e a Copel, com quatro indicadores entre os melhores no ano.

Tabela 6 - Indicadores referentes ao ano de 2012

\begin{tabular}{lrrrrrrrrrr}
\hline & $\begin{array}{l}\text { Liquidez } \\
\text { corrente }\end{array}$ & $\begin{array}{c}\text { Liquidez } \\
\text { geral }\end{array}$ & $\begin{array}{l}\text { Composição do } \\
\text { Endividamento }\end{array}$ & Endividamento & $\begin{array}{c}\text { Participação de } \\
\text { capital de } \\
\text { terceiros }\end{array}$ & $\begin{array}{l}\text { Giro do } \\
\text { Ativo } \\
\text { (vezes) }\end{array}$ & ROA & ROE & $\begin{array}{c}\text { Margem } \\
\text { liquida }\end{array}$ & $\begin{array}{c}\text { Margem } \\
\text { operacional }\end{array}$ \\
\hline Alupar & 1,62 & 1,73 & $26,46 \%$ & $57,91 \%$ & $137,61 \%$ & 0,16 & $12,53 \%$ & $17,53 \%$ & $44,87 \%$ & $82,53 \%$ \\
Cemig & 0,69 & 1,97 & $60,89 \%$ & $50,81 \%$ & $181,99 \%$ & 0,11 & $15,46 \%$ & $36,98 \%$ & $96,16 \%$ & $45,26 \%$ \\
CEB & 0,93 & 1,38 & $35,11 \%$ & $72,57 \%$ & $264,55 \%$ & 0,12 & $8,10 \%$ & $11,35 \%$ & $25,74 \%$ & $11,89 \%$ \\
CEEE-D & 1,72 & 1,24 & $37,13 \%$ & $80,83 \%$ & $421,72 \%$ & 0,05 & $1,50 \%$ & $-32,97 \%$ & $-130,78 \%$ & $2,39 \%$ \\
CEEE-G & 4,28 & 2,05 & $23,96 \%$ & $48,85 \%$ & $95,50 \%$ & 0,14 & $8,28 \%$ & $-4,70 \%$ & $-16,63 \%$ & $31,95 \%$ \\
Celesc & 1,00 & 1,50 & $36,62 \%$ & $66,74 \%$ & $200,63 \%$ & 0,08 & $-4,20 \%$ & $-14,39 \%$ & $-62,02 \%$ & $-5,08 \%$ \\
Celgpar & 0,10 & 0,16 & $42,53 \%$ & $608,32 \%$ & $-119,81 \%$ & 0,04 & $-188,48 \%$ & $37,62 \%$ & $-4590,76 \%$ & $-1329,71 \%$ \\
Cesp & 0,60 & 2,41 & $25,54 \%$ & $41,50 \%$ & $70,95 \%$ & 0,11 & $8,04 \%$ & $5,10 \%$ & $28,18 \%$ & $40,47 \%$ \\
Copel & 16,52 & 1,74 & $4,50 \%$ & $57,35 \%$ & $50,94 \%$ & 0,18 & $15,01 \%$ & $5,88 \%$ & $37,21 \%$ & $19,40 \%$ \\
CPFL & 1,12 & 1,38 & $23,63 \%$ & $72,72 \%$ & $266,54 \%$ & 0,08 & $10,52 \%$ & $15,30 \%$ & $51,69 \%$ & $23,60 \%$ \\
Emae & 2,86 & 2,37 & $16,74 \%$ & $42,11 \%$ & $72,75 \%-$ & 0,01 & $-8,66 \%$ & $-11,11 \%$ & $458,65 \%$ & $-52,95 \%$ \\
Equatorial & 1,28 & 1,37 & $38,37 \%$ & $72,89 \%$ & $268,92 \%$ & 0,09 & $7,14 \%$ & $8,25 \%$ & $25,04 \%$ & $22,98 \%$ \\
Light & 1,11 & 1,37 & $24,02 \%$ & $72,86 \%$ & $268,43 \%$ & 0,15 & $11,50 \%$ & $14,01 \%$ & $25,99 \%$ & $17,85 \%$ \\
Renova & 1,81 & 1,59 & $21,95 \%$ & $62,98 \%$ & $170,13 \%$ & 0,02 & $1,87 \%$ & $-0,61 \%$ & $-9,00 \%$ & $43,33 \%$ \\
Taesa & 5,85 & 1,75 & $11,72 \%$ & $57,25 \%$ & $133,94 \%$ & 0,12 & $12,49 \%$ & $14,38 \%$ & $52,29 \%$ & $106,26 \%$ \\
\hline
\end{tabular}

Fonte: Calculado pelos autores, conforme dados divulgados pelas empresas em 2012.

ReFAE - Revista da Faculdade de Administração e Economia, v. 8, n. 2, p. 155-171, 2017 
A Cemig apresentou cinco indicadores acima do terceiro quartil, que foram o endividamento, o ROA, o ROE a margem líquida e a margem operacional e a Alupar apresentou o giro do ativo, o ROA, o ROE e a margem operacional acima do terceiro quartil. A Emae e a Taesa apresentaram quatro indicadores, cada, acima do terceiro quartil, enquanto a CEEE-D apresentou os piores indicadores nesse ano em relação a amostra estudada.

Tabela 7 - Indicadores referentes ao ano de 2013

\begin{tabular}{|c|c|c|c|c|c|c|c|c|c|c|}
\hline & $\begin{array}{l}\text { Liquidez } \\
\text { corrente }\end{array}$ & $\begin{array}{l}\text { Liquidez } \\
\text { geral }\end{array}$ & $\begin{array}{l}\text { Composição do } \\
\text { Endividamento }\end{array}$ & Endividamento & $\begin{array}{l}\text { Participação de } \\
\text { capital de } \\
\text { terceiros }\end{array}$ & $\begin{array}{l}\text { Giro do } \\
\text { Ativo } \\
\text { (vezes) }\end{array}$ & ROA & ROE & $\begin{array}{l}\text { Margem } \\
\text { liquida }\end{array}$ & $\begin{array}{c}\text { Margem } \\
\text { operacional }\end{array}$ \\
\hline Alupar & 1,80 & 1,96 & $27,59 \%$ & $50,93 \%$ & $103,80 \%$ & 0,15 & $12,35 \%$ & $15,97 \%$ & $50,74 \%$ & $87,45 \%$ \\
\hline Cemig & 1,13 & 2,12 & $34,48 \%$ & $47,08 \%$ & $135,90 \%$ & 0,13 & $14,38 \%$ & $24,56 \%$ & $64,95 \%$ & $35,88 \%$ \\
\hline CEB & 0,58 & 1,29 & $47,42 \%$ & $77,71 \%$ & $348,60 \%$ & 0,09 & $0,99 \%$ & $-13,85 \%$ & $-34,39 \%$ & $1,50 \%$ \\
\hline CEEE-D & 0,86 & 1,21 & $48,75 \%$ & $82,94 \%$ & $486,22 \%$ - & 0,01 & $-7,73 \%$ & $-44,70 \%$ & $647,00 \%$ & $-10,24 \%$ \\
\hline CEEE-G & 3,10 & 2,20 & $32,03 \%$ & $45,36 \%$ & $83,02 \%-$ & 0,07 & $-8,61 \%$ & $-11,04 \%$ & $81,75 \%$ & $-37,11 \%$ \\
\hline Celesc & 1,12 & 1,61 & $42,74 \%$ & $62,02 \%$ & $163,29 \%$ & 0,15 & $7,33 \%$ & $9,30 \%$ & $24,26 \%$ & $8,47 \%$ \\
\hline Celgpar & 0,14 & 0,18 & $42,73 \%$ & $558,92 \%$ & $-121,63 \%$ & 0,01 & $8,28 \%$ & $-0,68 \%$ & $220,67 \%$ & $68,76 \%$ \\
\hline Cesp & 1,18 & 2,59 & $21,36 \%$ & $38,60 \%$ & $62,87 \%$ & 0,17 & $1,99 \%$ & $-2,10 \%$ & $-7,65 \%$ & $7,72 \%$ \\
\hline Copel & 1,40 & 1,17 & $32,88 \%$ & $85,54 \%$ & $78,76 \%$ & 0,18 & $15,78 \%$ & $8,52 \%$ & $51,42 \%$ & $20,46 \%$ \\
\hline CPFL & 1,48 & 1,40 & $22,05 \%$ & $71,66 \%$ & $252,81 \%$ & 0,08 & $9,89 \%$ & $10,79 \%$ & $40,05 \%$ & $20,97 \%$ \\
\hline Emae & 2,86 & 3,66 & $23,95 \%$ & $27,35 \%$ & $50,74 \%$ & 0,00 & $3,06 \%$ & $8,16 \%$ & $1496,98 \%$ & $22,51 \%$ \\
\hline Equatorial & 1,82 & 1,46 & $27,00 \%$ & $68,72 \%$ & $219,68 \%$ & 0,11 & $8,37 \%$ & $2,76 \%$ & $7,53 \%$ & $16,16 \%$ \\
\hline Light & 1,05 & 1,37 & $34,84 \%$ & $73,26 \%$ & $273,93 \%$ & 0,15 & $12,64 \%$ & $16,89 \%$ & $30,32 \%$ & $22,15 \%$ \\
\hline Renova & 0,30 & 1,36 & $51,69 \%$ & $73,35 \%$ & $267,00 \%$ & 0,04 & $3,32 \%$ & $0,63 \%$ & $4,90 \%$ & $53,51 \%$ \\
\hline Taesa & 1,63 & 1,89 & $22,63 \%$ & $52,97 \%$ & $112,64 \%$ & 0,16 & $15,67 \%$ & $20,74 \%$ & $61,67 \%$ & $99,10 \%$ \\
\hline
\end{tabular}

Fonte: Calculado pelos autores, conforme dados divulgados pelas empresas em 2013.

A Alupar apresentou quase todos indicadores de liquidez e rentabilidade acima da média no ano de 2013, com exceção da margem líquida, que está igual à média; os indicadores de endividamento estão abaixo da média. A Cemig, também, possui quase todos os indicadores acima da média no ano de 2013, com exceção da liquidez corrente e da composição do endividamento; em relação ao endividamento a Cemig o reduziu em todos os anos, começando com 65,80\% em 2010 e apresentou o endividamento de 47,08\% em 2013, o que mostra diminuição da relação entre o passivo exigível total e ativo total da empresa. $\mathrm{O}$ destaque do grupo das empresas não internacionalizadas foi, novamente, a Taesa, com todos os indicadores acima da média em 2013 e o destaque negativo foi a CEEE-D com todos os indicadores abaixo do primeiro quartil em 2013.

Após o cálculo dos indicadores econômico-financeiros de cada empresa, cálculo dos quartis e atribuição das notas avaliativas para cada intervalo quartílico pode-se verificar que a Alupar e a Cemig estiveram entre as empresas com maior pontuação em todos os anos. A Alupar foi classificada em $2^{\circ}$ em 2010, em $1^{\circ}$ em 2011, em $2^{\circ}$ em 2012 e em $3^{\circ}$ em 2013, já a Cemig foi classificada em $4^{\circ}, 3^{\circ}, 3^{\circ}$ e $2^{\circ}$, nesses anos, respectivamente. Apenas a Taesa, não internacionalizada obteve avaliação superior às internacionalizadas no período, ou seja, as 
empresas Alupar e Cemig apresentaram indicadores melhor avaliados em relação a 12 das 13 empresas não internacionalizadas estudadas, conforme Tabela 8.

Tabela 8 - Resultado da avaliação

\begin{tabular}{lcccc}
\hline & 2010 & 2011 & 2012 & 2013 \\
\hline Alupar & 32 & 31 & 33 & 30 \\
Cemig & 27 & 28 & 30 & 31 \\
CEB & 17 & 18 & 21 & 13 \\
CEEE-D & 13 & 18 & 13 & 10 \\
CEEE-G & 25 & 25 & 29 & 25 \\
Celesc & 24 & 23 & 16 & 25 \\
Celgpar & 18 & 18 & 16 & 22 \\
Cesp & 22 & 25 & 28 & 26 \\
Copel & 27 & 29 & 33 & 27 \\
CPFL & 26 & 27 & 25 & 25 \\
Emae & 23 & 24 & 27 & 32 \\
Equatorial & 29 & 27 & 16 & 24 \\
Light & 23 & 23 & 25 \\
Renova & 23 & 23 & 25 & 18 \\
Taesa & 29 & 29 & 34 & 35 \\
\hline & 35 & Fonte: Elaborado pelos autores. & &
\end{tabular}

Em seguida, testou-se a hipótese de que as amostras de empresas internacionalizadas e não internacionalizadas tenham sido provenientes de populações com médias iguais no que tange a cada índice, por meio do teste não paramétrico de Mann-Whitney, de acordo com Martins e Domingues (2011), com base nos dados do período 2010-2013. Obteve-se, ao nível de significância de 5\%, que há diferença entre as médias de empresas internacionalizadas e não internacionalizadas no que tange aos índices de rentabilidade, isto é, para ROA $(\mathrm{p}=0,0037), \operatorname{ROE}(\mathrm{p}=0,00001)$, Margem líquida $(\mathrm{p}=0,0084)$ e Margem operacional $(\mathrm{p}=0,00032)$. Cabe notar que a quantidade de empresas internacionalizadas estudada impossibilitou a realização desse teste para o estabelecimento de comparações entre médias anuais dos dois grupos.

\section{CONSIDERAÇÕES FINAIS}

As empresas internacionalizadas alcançaram resultados que as posicionam entre as melhores, em termos do conjunto de índices econômico-financeiros adotado, ficando situadas entre as primeiras colocações na avaliação estabelecida. Pode-se verificar a partir da Tabela 8 , que Alupar e Cemig ficaram aquém apenas da não internacionalizada Taesa. As empresas internacionalizadas, notadamente a Alupar, apresentaram resultados econômico-financeiros 
que vão ao encontro de Gallina, Fleury e Bulba (2005), pois houve aumento no lucro líquido dessas empresas após a internacionalização.

É necessário destacar que inferências para o segmento energia elétrica não podem ser efetuadas a partir dos resultados da presente pesquisa, porque a amostra utilizada não seguiu critério probabilístico. Limitação adicional do estudo está relacionada à escolha dos indicadores econômico-financeiros empregados na análise, pois resultados poderiam ser diferentes com outra seleção de índices.

Futuros estudos, voltados para outros segmentos de empresas podem ser conduzidos de forma semelhante com a inclusão de indicadores e análise de dados com base em mais informações específicas de cada empresa.

\section{REFERÊNCIAS}

ALUPAR, disponível em <www.ri.alupar.com.br>, acesso em 01 abr 2015.

ANEEL, Agência Nacional de Energia Elétrica, disponível em www.aneel.gov.br acesso em 30 mar 2015.

ANEEL, Agencia Nacional de Energia Elétrica, disponível em <www.aneel.gov.br/aplicacoes/capacidadebrasil/capacidadebrasil.cfm>, acesso em $30 \mathrm{abr}$ $2015^{\mathrm{a}}$.

ASSAF NETO, A.; LIMA, F.G., Curso de administração financeira. São Paulo, SP: Atlas, 2011.

BM\&FBovespa, disponível em <www.bmfbovespa.com.br> acesso em 07 nov. 2013.

BCB Banco Central do Brasil, disponível em <www.bcb.gov.br/?SERIEFIND>, acesso em 18 mai 2015.

CEB, disponível em <www.sitelite.mz-ir.com/ceb>, acesso em 01 abr 2015.

CEEE-D, disponível em <www.ri.ceee.com.br>, acesso em 01 abr 2015.

CEEE-GT, disponível em <www.ri.ceee.com.br>, acesso em 01 abr 2015.

CELESC, disponível em <www.celesc.firbweb.com.br>, acesso em 01 abr 2015.

CEMIG, disponível em <www.cemig.infoinvest.com.br>, em 01 abr 2015.

CESP, disponível em <www.ri.cesp.com.br>, acesso em 01 abr 2015.

COPEL, disponível em <www.copel.com/hpcopel/ri>, em 01 abr 2015.

CUNHA, M. F.; MARTINS, E.; ASSAF NETO, A. A Finalidade da Avaliação de Empresas, no Brasil, Apresenta Viés?: Evidências empíricas sob o ponto de vista do desempenho econômico-financeiro. Contabilidade Vista \& Revista, v. 23, n. 3, p. 15-47, 2012. 
DUNNING, J. H., The Eclectic (OLI) Paradigm of international production: past, present and future. International journal of the economics of business, v. 8, n. 2, p. 173-190, 2001.

EMAE, disponível em <www.emae.com.br/ri>, acesso em 01 abr 2015.

EMPRESA DE PESQUISA ENERGÉTICA (EPE). Balanço Energético Nacional 2014: Ano base 2013 / Empresa de Pesquisa Energética. - Rio de Janeiro: EPE, 2014.

EQUATORIAL, disponível em <www.equatorialenergia.com.bri>, acesso em 01 abr 2015.

GALliNA, R.; FlEURY, A. C. C.; BULBA, A. E., O Processo de Internacionalização de Uma Empresa Brasileira do Setor de Autopeças. In: XI Seminário Latino-Iberoamericano de Gestion Tecnológica - ALTEC 2005, 2005, Salvador, 2005.

JOHANSON, J.; VAHLNE, J-E. The Uppsala internationalization process model revisited: From liability of foreignness to liability of outsidership. Journal of International Business Studies, v. 40, p.1411 - 1431, 2009. Disponível em: <http://search.proquest.com/docview/197134746/13A67519EE5196EBA5C/1 ?accountid=146 43>. Acesso em: 30 mai 2010.

The internationalization process of the firm - a model of knowledge development and increasing foreign market commitments. Journal of International Business Studies, v.8, p.23-32, $1977 . \quad$ Disponível em: http://search.proquest.com/docview/197407744/13A674B4CFD22376471/1?accountid=1464 3 Acesso em: 20 jun 2009.

LIGHT, disponível em <www.ri.light.com.br>, acesso em 01 abr 2015.

MACADAR, B. M. A internacionalização de grandes empresas brasileiras e as experiências do Grupo Gerdau e da Marcopolo. Ensaios FEE, Porto Alegre, v. 30, n. 1, p. 7-34, mai. 2009. MARTINS, G. A.; THEÓPHILO, C. R. Metodologia da investigação científica para ciências sociais aplicadas. São Paulo: Atlas, 2009.

MARTINS, G. A.; DOMINGUES, O. Estatística geral e aplicada. São Paulo: Atlas, 2011. MATARAZZO, D. C., Análise Financeira de Balanços: abordagem gerencial. São Paulo: Atlas, 2010.

ONS - Operador Nacional do Sistema Elétrico, disponível em <www.ons.org.br/historico>, acesso em 01 abr 2015.

RENOVA, disponível em <www.renovaenergia.com.br/ri>, acesso em 01 abr 2015.

RIBEIRO, F.F; OLIVEIRA Jr., M. M.; BORINI, F. M., Internacionalização Acelerada de Empresas de Base Tecnológica: o Caso das Born Globals Brasileiras, RAC - Revista de Administração Contemporânea, Rio de Janeiro, v. 16, n. 6, art. 6, p.866-888, Nov./Dez. 2012

ReFAE - Revista da Faculdade de Administração e Economia, v. 8, n. 2, p. 155-171, 2017 
ROCHA, A.; ALMEIDA, V. Estratégias de entrada e de operações em mercados internacionais. In: TANURE, B.; DUARTE, R. G. (Org.), Gestão Internacional. São Paulo: Saraiva, 2006.

TAESA, disponível em <www.ri.taesa.com.br>, acesso em 01 abr 2015.

UNCTAD. Trade and Development Report, 2012: Policies for Inclusive and Balance Growth. New York: United Nations, 2012. Disponível em: <http://unctad.org/en/PublicationsLibrary/tdr2012_en.pdf> Acesso em 15 nov 2013.

VIANNA, N.W.H.; PISCOPO, M.R.; RYNGELBLUM, A.L. Internacionalização da pequena e média empresa brasileira: o caso da indústria de máquinas-ferramenta. Revista Base, v. 10, p. 210-223. 